\title{
GEOSUL
}

\section{MODIFICAÇÕES NOS ESPAÇOS PERCEBIDO, CONCEBIDO E VIVIDO EM CHAPECÓ-ŞC DEVIDO À ASSOCIAÇÃO CHAPECOENSE DE FUTEBOL NO PERÍODO DE 2014 A 2016}

Fernando Rosseto Gallego Campos ${ }^{1}$

Resumo: A Associação Chapecoense de Futebol possui grande importância social, cultural, simbólica e econômica para Chapecó-SC e região. Desde de 2014, o clube disputa a Série A do Campeonato Brasileiro, gerando mudanças sociais e espaciais. Assim, nosso objetivo é analisar as modificações nas instâncias do percebido, concebido e vivido da espacialidade de Chapecó devido ao sucesso da Chapecoense, no período de 2014 a 2016. Além de pesquisa documental, foram realizadas observações de campo, 21 entrevistas e aplicados 157 questionários no comércio. No espaço de representação do futebol (dimensão do vivido), a Chapecoense aumentou sua influência local, estadual, nacional e internacionalmente em diferentes aspectos. Já nos espaços percebido e concebido, houve aumento na participação do clube na vida cotidiana dos habitantes de Chapecó, bem como cresceu a apropriação política e econômica do clube, sobretudo em Chapecó e região.

Palavras-chave: Futebol; Chapecó; Chapecoense; Espacialidade; Espaço de Representação.

\section{CHANGES IN PERCEIVED, CONCEIVED AND LIVED SPACES IN CHAPECÓ-SC DUE TO THE ASSOCIAÇÃO CHAPECOENSE DE FUTEBOL FROM 2014 TO 2016}

\begin{abstract}
The Associação Chapecoense de Futebol has a great social, cultural, symbolical, and zeconomical importance to Chapecó-SC and region. Since 2014, the club disputes the Brazilian League's main division (Série A) generating social and spatial changes. Thus, this article aims at analysing the changes in perceived, conceived and lived spatiality instances in Chapecó due to Chapecoense's success from 2014 to 2016 . Besides documentary research, field observations were made, 21 interviews were carried out, and 157 questionnaires were administered in the commercial establishments. In football representational space (lived instance), Chapecoense increased its influence at the local, regional, national and international levels in different aspects. Chapecoense's participation in the everyday life of the people who live in Chapecó increased along with the political and economical appropriation of Chapecoense in Chapecó and region both in the perceived and lived spaces.
\end{abstract}

Keywords: Football; Chapecó; Chapecoense; Spatiality; Representational Space.

\footnotetext{
${ }^{1}$ Instituto Federal de Santa Catarina (IFSC) - Câmpus Chapecó. Email: fgallego@gmail.com
} 


\section{MODIFICACIONES EN LOS ESPACIOS PERCIBIDO, CONCEBIDO Y VIVIDO EN CHAPECÓ-SC DEBIDO A LA ASSOCIAÇÃO CHAPECOENSE DE FUTEBOL EN EL PERÍODO ENTRE 2014 Y 2016}

Resumen: La Associação Chapecoense de Futebol tiene gran importancia social, cultural, simbólica y económica para Chapecó-SC y región. Hasta 2014, el club disputa la Série A del Campeonato Brasileño, generando cambios sociales y espaciales. De esta forma, nuestro objetivo es analizar las modificaciones en las instancias de lo percibido, concebido y vivido de la espacialidad de Chapecó debido al suceso de Chapecoense, en el período entre 2014 y 2016. Allá de la investigación documental, fueron realizadas observaciones de campo, 21 entrevistas y aplicados 157 cuestionarios en le comercio. En el espacio de representación del fútbol (instancia de lo vivido), la Chapecoense ha aumentado su influencia local, nacional y internacionalmente en diferentes aspectos. Ya en los espacios percibido y concebido, ha habido aumento en la participación del club en la vida cotidiana de los residentes habitantes de Chapecó, así como ha crecido la apropiación política y económica del club, especialmente en Chapecó y región.

Palabras clave: Fútbol; Chapecó; Chapecoense; Espacialidad; Espacio de Representación.

\section{INTRODUÇÃO}

O desastre de avião ocorrido em 29 de novembro de 2016 deslocou todos os olhares do mundo do futebol para a Associação Chapecoense de Futebol. A tragédia, noticiada e coberta nacional e internacionalmente, trouxe uma exposição inédita ao clube do Oeste Catarinense, que disputaria sua primeira final internacional. Para chegar à decisão da Copa Sul-americana, a Chapecoense teve uma rápida ascensão esportiva, econômica e de estrutura de 2009 quando jogou a Série D até 2016, seu terceiro ano consecutivo na Série A do Campeonato Brasileiro.

O caso da Chapecoense é uma exceção no futebol brasileiro não apenas pela velocidade com a qual subiu da Série D (mais baixa divisão nacional) para a elite do futebol brasileiro. $\mathrm{O}$ clube tem sede em Chapecó, um município com 209.556 habitantes (IBGE, 2016) localizada no interior do estado de Santa Catarina. Poucos clubes de cidades deste porte conseguem chegar até a Série A do Campeonato Brasileiro, sendo que, desde 2006, a Chapecoense é o clube de municípios com menos de 300 mil habitantes com mais participações no principal campeonato 
nacional. Além disso, fica em uma cidade de interior (cerca de 550 km da capital, Florianópolis) em um estado que não figura tradicionalmente entre os maiores polos futebolísticos do país (Santa Catarina não tem nenhum título da Série A, mas ocupa atualmente a quinta colocação entre as federações estaduais no ranking da Confederação Brasileira de Futebol - CBF) (CBF, 2017).

A Chapecoense foi fundada em 1973, através da iniciativa de futebolistas amadores de se criar o primeiro clube profissional da cidade (BELLANI, 2007). Dois anos antes, em meio à ditadura militar (e, inclusive, impulsionado por ela) e após a euforia da conquista da Taça Jules Rimet, foi criado o Campeonato Brasileiro - competição que pela primeira vez integraria futebolisticamente o território nacional (apesar de ter havido outras competições nacionais anteriores) (MASCARENHAS, 1999; BELLANI, 2007). Localmente, Chapecó experimentava importante crescimento econômico e de influência política no entorno, processo que se consolidou nas décadas posteriores. Ter um clube profissional (e forte) na cidade poderia reforçar este papel regional e estadual, bem como render à cidade participações na maior competição nacional, já que, por um período, as vagas no Campeonato Brasileiro eram definidas nos campeonatos estaduais.

No entanto, até a década de 2010, a Chapecoense havia participado apenas duas vezes da elite do Campeonato Brasileiro (devido ao desempenho no Campeonato Catarinense), em 1978 (12 jogos) e 1979 (9 jogos). Ao conquistar o vice-campeonato da Série B do Campeonato Brasileiro de 2013, pela primeira vez, o clube conseguiu vaga na Série A do Campeonato Brasileiro através de uma divisão de acesso nacional. As participações da Chapecoense na Série A a partir de 2014 não se diferem das anteriores somente pela forma de acesso, mas também pelo status que o clube atingiu nacionalmente (a partir de 2006 apenas 20 clubes de todo o país disputam a Série A, enquanto os campeonatos brasileiros de 1978 e 1979 tiveram respectivamente 74 e 80 participantes) e pela quantidade de jogos (38 no total, sendo 19 em Chapecó). Além disso, todos os jogos da Chapecoense são televisionados para todo o Brasil (pay per view e alguns por TV a cabo e TV aberta). Há também maior exposição do clube nos portais de notícia e sites especializados de todo o Brasil, entre outras mídias, inclusive internacionais. Desta forma, com exceção ao período posterior ao acidente aéreo - o qual não 
analisaremos -, no período entre 2014 e 2016, a Chapecoense experimentou uma evidência sem precedentes na sua história.

A participação da Chapecoense na Série A vem movimentando o espaço de representação do futebol de Chapecó - instância da espacialidade do vivido, em que se dá a experiência do futebol (GALLEGO CAMPOS, 2006; LEFEBVRE, 1991). O espaço de representação do futebol se articula trialeticamente de diversas formas e em diferentes níveis de intensidade com outras instâncias da espacialidade lefebvriana: a da prática espacial (percebido) e das representações do espaço (concebido) (LEFEBVRE, 1991; SOJA, 1996; GALLEGO CAMPOS, 2006). É possível afirmar, inclusive, que este período é ímpar na articulação entre as três instâncias da espacialidade em Chapecó, no que se refere ao futebol, ou seja, o espaço de representação do futebol de Chapecó ganhou importância na vida da cidade de forma a se relacionar e influenciar o cotidiano das pessoas (instância prática espacial) e as instituições públicas e privadas (instância representações do espaço), recebendo influência destas instâncias também. Tais complexas interações envolvem diferentes dimensões, entre elas a econômica, a política, a social, a esportiva, a cultural, entre outras.

É fundamental que se investigue como se dão estas relações entre as instâncias da espacialidade na cidade de Chapecó por ocasião da participação da Chapecoense na Série A. Assim, esta pesquisa tem como objetivo analisar as modificações nas instâncias da espacialidade lefebvriana em Chapecó devido ao sucesso da Associação Chapecoense de Futebol, no período de 2014 a 2016.

Para tal articulamos o referencial teórico com uma pesquisa de campo junto à Chapecoense - pesquisa documental, levantamento de dados, observações, visitas ao clube, entrevistas - e a outras instituições públicas e privadas - prefeitura, empresas patrocinadoras e conveniadas e mídia local. Além disso, foram feitas observações de campo, bem como aplicação de questionários em 157 estabelecimentos sobre impactos do acesso da Chapecoense à Série A no comércio local.

No total, foram realizadas 21 entrevistas semiestruturadas com atores socioespaciais significativos, com duração entre 15 minutos e 1 hora e 15 minutos. Os entrevistados foram escolhidos a partir de sua importância/relevância na constituição do espaço de representação do 
futebol de Chapecó, bem como por sua capacidade de analisar as mudanças ocorridas no mesmo. Foram entrevistados jogadores, funcionários do clube, dirigentes, empresários locais, representante do poder público, torcedores e membros da imprensa (ver descrição completa nas Referências - Entrevistas). Todos os entrevistados autorizaram a publicação das entrevistas.

No início das entrevistas, era pedido para que os entrevistados falassem sobre sua relação com o clube. Posteriormente, as entrevistas se desenvolviam conforme as respostas dadas. Os entrevistados eram estimulados a falar sobre as mudanças ocorridas no clube e na cidade (eventualmente, eram temáticas abordadas espontaneamente pelos entrevistados, sem a necessidade de uma pergunta específica sobre este assunto). Não se seguiu um roteiro de perguntas devido à heterogeneidade dos participantes, privilegiando-se, portanto, as idiossincrasias das pessoas ou dos grupos dos quais fazem parte. $\mathrm{O}$ artigo não trará transcrição de trechos das entrevistas devido à limitação de páginas.

\section{ESPACIALIDADE}

O espaço, para Henri Lefebvre (1991), possui papel central na organização social. Ele é, dialeticamente, produto social e produtor da sociedade. A espacialização das relações sociais é condição para a existência destas, sendo o espaço social o próprio repositório da autenticidade (SHIELDS, 1999). Apesar da base no pensamento crítico, a leitura lefebvriana avança em relação a abordagens que veem o espaço apenas como base material (fonte de recursos ou mero substrato no qual se enraízam as sociedades e suas obras). Em relação dialética tripla (LEFEBVRE, 1991), a espacialidade, a historicidade e a socialidade formam a trialética da existência (SOJA, 1996).

A concepção de Lefebvre (1991) do espaço como produto social traz quatro grandes implicações: a) o desaparecimento gradativo do espaço físico (natural) devido à artificialização e à apropriação social e econômica da natureza; b) cada sociedade ou modo de produção produz o seu espaço próprio a partir das relações de produção e de reprodução e das representações, 
surgindo a tríade espacial (prática espacial, representações do espaço e espaços de representação); c) não basta conhecermos os elementos do espaço, mas sobretudo o seu processo de produção em suas três dimensões (percebido, concebido e vivido); d) o espaço tem caráter histórico, havendo quatro etapas (espaço absoluto, espaço abstrato, espaço contraditório e espaço diferencial).

Desta forma, a complexidade da espacialidade lefebvriana vai além das relações materiais de produção e reprodução, se estendendo também a dimensões simbólicas, que ocupa parte fundamental na constituição do espaço social. A espacialidade possui caráter tríade, articulando-se em três instâncias, que mantêm relações dialéticas - dialética da triplicidade (LEFEBVRE, 1991) ou, nas palavras de Soja (1996) trialética.

As instâncias prática espacial (dimensão do percebido) e representações do espaço (dimensão do concebido) (LEFEBVRE, 1991), primeiro e segundo espaços, respectivamente, para Soja (1996), possuem íntima relação, o que impossibilita uma análise desassociada dos mesmos. Entretanto, a separação destas duas instâncias da espacialidade é um exercício teórico de extrema importância, inclusive, para a compreensão do grau em que estão conectadas, o que varia histórica e geograficamente.

A prática espacial compreende a dimensão das relações materiais do espaço social, bem como das expressões - não refletidas, alienadas e de ausência - da vida cotidiana (LEFEBVRE, 1991; 2006). Para Lefebvre, esta instância, que corresponde ao espaço percebido, é expressão da produção espacial de uma sociedade e, dialeticamente, se expressa nas próprias relações materiais: "A prática espacial de uma sociedade secreta o espaço desta sociedade; ela o propõe e o pressupõe, em uma interação dialética; ela o produz vagarosa e seguramente conforme o domina e dele se apropria” (LEFEBVRE, 1991, p. 38, tradução nossa).

Já a instância das representações do espaço (espaço concebido) é a dominante da espacialidade (ou tem pretensão de tal), pois é a expressão do poder, das instituições, das coerções, das ideologias (LEFEBVRE, 1991). É a instância do planejamento (urbano), que contribui com as relações de reprodução, sendo diametralmente oposta à instância dos espaços de representações (SOJA, 1996). Desta forma, as manifestações da prática espacial tendem a reproduzir o concebido nas representações do espaço. 
A instância dos espaços de representação (espaço vivido) é justamente a dimensão que rompe com leituras que consideram apenas as relações de produção e reprodução, fornecendo grande contribuição para uma abordagem cultural e social em geografia, calcada em elementos simbólicos. Isto porque, segundo Lefebvre (1991; 2008), os espaços de representação se expressam como o rompimento com a vida cotidiana alienada (percebido) e com a estrutura institucional alienante (concebido), criando experiências plenamente vividas, como é o caso do futebol. Este rompimento se dá através de momentos de presença, ou seja, de experiências plenamente vividas (LEFEBVRE, 2006). Por se tratar de uma instância eminentemente simbólica, perpassa o espaço material e cria um universo próprio de relações e experiências, mesmo que objetivamente ligado às demais instâncias da espacialidade (LEFEBVRE, 1991; SOJA, 1996; GIL FILHO, 2003).

Estas instâncias, que são difíceis de serem delimitadas por estarem intrinsecamente conectadas, experimentam diferentes equilíbrios no processo histórico de produção do espaço em um meio de produção (o que também pode ser transportado para uma sociedade, no caso a de Chapecó). A seguir, abordaremos as mudanças ocorridas em cada uma das instâncias do percebido, concebido e vivido devido ao sucesso da Chapecoense, considerando, sobretudo, o período entre 2014 e 2016. A separação entre as instâncias não tem como objetivo simplificálas nem tratá-las como coisas ou lugares separados, mas visa facilitar a análise e tornar mais clara sua apreensão. Além disso, tal separação contribui para compreender como a dimensão do vivido, sobretudo o espaço de representação do futebol, vem aumentando sua importância na espacialidade chapecoense, contribuindo para o estabelecimento de um espaço diferencial (LEFEBVRE, 1991).

\section{MUDANÇAS NO ESPAÇO DE REPRESENTAÇÃO DO FUTEBOL}

Os impactos futebolísticos são os mais óbvios e, portanto, começaremos por eles, mesmo que se refiram de forma mais direta à terceira instância da espacialidade lefebvriana: os espaços de representação. 
Se os espaços de representação são diversos em apropriações de seus elementos, podemos dividi-los de acordo com seus universos simbólicos. Desta ideia deriva nossa concepção do(s) espaço(s) de representação do futebol, instância das experiências futebolísticas puramente vividas e locus das relações simbólicas (e materiais) derivadas de tais experiências (GALLEGO CAMPOS, 2006). Ele é composto pelos círculos: (1) das categorias centrais (fato futebolístico, prática social do futebol e relações), que em sua interação formam o espaço de representação do futebol; (2) dos reinos (organização, emoções e ethos futebolístico), que se expressam como representações sociais; (3) e das categorias de mediação (símbolo, mito, discurso e estruturação identitária futebolística), que mediam e expressam as relações entre os elementos dos outros dois círculos (GALLEGO CAMPOS, 2006). Em cada espaço de representação do futebol estes elementos podem ser apropriados de maneira distinta, produzindo diferentes configurações simbólicas, identitárias, culturais, futebolísticas, econômicas e políticas, bem como produzindo diferentes territorialidades.

Diferentemente do território, que pressupõe os processos de dominação e apropriação, apontados por Lefebvre (1991), a territorialidade tem fundamento simbólico, sendo construída a partir (apenas) da apropriação de determinado espaço ou reapropriação de um dado território (sem que haja a necessidade de dominação prévia). No espaço de representação do futebol, estas territorialidades se expressam através de símbolos (cores do clube, escudo, etc.), mitos (grandes jogadores, grandes times, etc.), discursos (do clube e dos atores socioespaciais, conforme analisaremos como forma de apreensão das relações do espaço de representação do futebol) e através da estruturação identitária futebolística, que está conectada com a identidade no sentido mais amplo. Segundo Hall (2005), a identidade na pós-modernidade perde sua atribuição de fixar o sujeito à estrutura. Este, assim, passa a assumir uma diversidade de identidades em diferentes situações e momentos de sua vida. Entretanto, mesmo tendo caráter híbrido (HALL, 2005), afetual e proxêmico (MAFFESOLI, 2006), a estruturação identitária futebolística possui peculiaridades, sobretudo no que se refere à sua mutabilidade. Em outras palavras, enquanto as estruturações identitárias se tornam mais fluídas, a identidade futebolística continua tendo caráter mais fixo, pois o clubismo pressupõe fidelidade e, preferencialmente, eterna.(GALLEGO CAMPOS, 2006; DAMO, 2012). 
A participação na Série A fez com que a Chapecoense entrasse no seleto grupo dos 20 clubes na elite do futebol brasileiro. Mesmo com um orçamento inferior à maioria dos seus adversários no Campeonato Brasileiro, o clube consegue se manter na Série A de um dos campeonatos nacionais mais disputados do mundo desde 2014, se consolidando como um dos maiores clubes do futebol nacional na atualidade, bem como tendo oportunidade de se estruturar: construção de um centro de treinamento próprio (CT da Água Amarela), montagem de uma academia de última geração, mudança de sede, investimento no corpo de funcionários, etc. Outra mudança bastante significativa foi a ampliação do estádio. De propriedade da Prefeitura Municipal de Chapecó, até o final de 2013, a Arena Condá possuía capacidade para 12,8 mil torcedores, o que era insuficiente para receber jogos da Série A. Com um aporte financeiro de R \$ 6,7 milhões do Governo do Estado de Santa Catarina, foi feita uma reforma, que aumentou a capacidade para 20 mil lugares e que tornou o estádio mais moderno, confortável e melhor para a prática do futebol (ajuste no tamanho do campo, melhoria no gramado, etc.). Esta reforma concluiu o processo de modernização do estádio, que se iniciou em 2008, quando também mudou de nome de Estádio Regional Índio Condá para Arena Condá, simbolizando este processo, conforme aponta Mascarenhas (2013). No entanto, ao contrário do que autor relata em vários locais, não houve um superdimensionamento nem uma pasteurização dos espaços, modificando substancialmente as formas de torcer. A maior mudança de disciplinarização dos torcedores foi a proibição da entrada de torcedores com camisas de outros clubes, sobretudo Grêmio e Internacional sob o argumento que isto enfraqueceria as laços entre clube e torcedores (Informação verbal ${ }^{2}$ ).

Esta permanência na elite futebolística não se converteu apenas em benefícios esportivos apenas, mas também aumentou o peso institucional do clube estadual e nacionalmente, bem como contribui na expansão de seus elementos simbólicos, sobretudo em Chapecó e na região oeste de Santa Catarina - o que pode se reverter no aumento do número de torcedores e no consumo da marca.

Para os entrevistados ligados ao clube, o acesso à Série B marcou a virada no futebol da Chapecoense, que esteve para fechar em 2005, devido à crise financeira (Informação verbał $7^{3} 4$ Nesta época, um grupo de empresários da cidade, bem como pessoas ligadas ao poder público e a diversos setores da sociedade chapecoense assumiram a gestão do clube, que passou a ser

\footnotetext{
${ }^{2}$ AGNOLETTO, 2015; ANDRADE; BADALOTI, 2015; PALLAORO, 2015; RODRIGUES, 2015; SOUZA, 2015; VALMORBIDA, 2015.

${ }^{3}$ ARAÚJO, 2015; BORDIGNON, 2015; CONSTANTE, 2015; LIMA, 2015; NÊS FILHO, 2015; PALLAORO, 2015; RODRIGUES, 2015; SANTOS, 2015; SOUZA, 2015; STUMPF, 2015; VIVIAN, 2015.
} 
administrado a partir de uma lógica empresarial (Informação verbal ${ }^{4}$ ). No entanto, era necessário aumentar a receita do clube e isto só era possível se garantindo calendário para o ano todo e, portanto, participando das principais divisões do futebol brasileiro. As Séries C e D possuem duração menor, menos jogos garantidos (possuem fases eliminatórias) e menos exposição, consequentemente as verbas televisivas recebidas são sensivelmente menores.

A Chapecoense subiu da Série D para a Série C em 2009, para a Série B em 2012 e para a Série A em 2013. Esta ascensão tão rápida não estava nos planos do clube, que tinha como objetivo se manter por cinco anos na Série B para se estruturar e só então efetivamente tentar um acesso à Série A (Informação verbal ${ }^{5}$ ). Jogar na elite do futebol brasileiro não apenas garantiu calendário o ano todo, mas um aumento considerável nas receitas, que passaram de 12,5 milhões em 2013 para aproximadamente R \$ 34,5 milhões em 2014, R \$ 46,4 milhões em 2015 e R\$ 62,4 milhões em 2016 (ASSOCIAÇÃO, 2016). Só a verba advinda da venda do direito de transmissão para televisão aberta gira em torno de $\mathrm{R} \$ 29$ milhões (em 2013, o clube recebia a cota mínima da Série $B$, de cerca de $\mathrm{R} \$ 3$ milhões). Já o valor pago pelo patrocinador máster da camisa (Caixa Econômica Federal) foi de R \$ 1 milhão em 2013 para R \$ 4 milhões em 2016 (ASSOCIAÇÃO, 2016). Isto permitiu, além do investimento na estrutura do clube, contratar jogadores de renome nacional, que vieram atraídos pelo projeto de crescimento do clube, pelo fato do clube honrar com seus compromissos financeiros e também pelas características da cidade (Informação verbal ${ }^{6}$ ).

A imagem da Chapecoense teve grande mudança não apenas entre os jogadores. De um clube modesto, de territorialidades circunscritas à escala local (Oeste Catarinense e Santa Catarina), a Chapecoense construiu territorialidades nacionais e internacionais. Localmente, o sucesso do clube propiciou a redefinição das estruturas identitárias futebolísticas, que, em geral, são elementos pouco dinâmicos, pois não é comum um torcedor trocar de clube (; GALLEGO CAMPOS, 2006; DAMO, 2012; FRANCO JÚNIOR, 2013). No entanto, a torcida da Chapecoense não apenas cresceu, mas também mudou sensivelmente de perfil. Entrevistados ligados ao clube declararam que era comum ver torcedores em jogos da Chapecoense com camisas de clubes gaúchos, sobretudo Grêmio e Internacional, o que, em alguns momenł甲 95

\footnotetext{
${ }^{4}$ AGNOLETTO, 2015; ARAÚJO, 2015; BADALOTI, 2015; BENINI, 2015; BORDIGNON, 2015; DÁVI, 2015; VALMORBIDA, 2015; LANG, 2015; NÊS FILHO, 2015; PALLAORO, 2015; PERONE, 2015; SANTOS, 2015; STUMPF, 2015; VIVIAN, 2015; ZANONI, 2015.

${ }^{5}$ PALLAORO, 2015.

${ }^{6}$ FELISBINO, 2015; STUMPF, 2015.
} 
incomodava (Informação verbal ${ }^{7}$ ). Tal mudança não ocorreu apenas devido à disciplinarização no estádio, mas também porque houve um aumento na torcida da Chapecoense, bem como no orgulho de torcer pelo clube da cidade.

O clube catalisou um orgulho local, que convive com a tradição advinda do processo de ocupação de Chapecó, com forte matriz gaúcha. Todavia, esta convivência se dá atualmente em uma lógica de duplicidade. Se por um lado, grande parte $(84,3 \%)$ dos torcedores da Chapecoense declararam torcer também por outro clube, principalmente por clubes gaúchos $(67,4 \%)$ - o que demonstra a forte influência do espaço de representação do futebol gaúcho em Chapecó seja por questões de origem dos chapecoenses seja por questões midiáticas - por outro lado, há um movimento de valorização da Chapecoense como o clube da cidade e da região oeste. Esta última lógica pode ser observada: (1) pela elevada porcentagem de torcedores da Chapecoense em Chapecó (57,4\% do total e 67,9\% dos que declararam torcer ao menos por um clube) (GALLEGO CAMPOS; BETTONI, 2016), sobretudo entre os mais jovens; (2) pelo movimento da diretoria do clube para construir a imagem da Chapecoense como clube da região Oeste de Santa Catarina, mas também do Sudoeste do Paraná e Noroeste do Rio Grande do Sul, o que pode ser observado pela fundação e atuação de consulados, como os de Pinhalzinho-SC, Palmitos-SC, São Miguel do Oeste-SC e Francisco Beltrão-PR; e (3) pelo movimento de reconstrução das estruturações identitárias futebolísticas locais, através do discurso da Chapecoense como único time do torcedor de Chapecó (Informação verbal ${ }^{8}$ ).

A ascensão da Chapecoense provocou mudanças físicas e simbólicas na cidade de Chapecó. Algumas das mudanças mais significativas e sensíveis se deram no estádio e no seu entorno. Fisicamente, o Estádio Regional Índio Condá sofreu uma grande reforma (modernização e aumento de capacidade) e passou a se chamar Arena Condá (inaugurada em 2009 e ampliada significativamente para a Série A de 2014). No entanto, houve importantes

${ }^{7}$ AGNOLETTO, 2015; ANDRADE, 2015; BADALOTI, 2015; PALLAORO, 2015; RODRIGUES, 2015; SOUZA, 2015; VALMORBIDA, 2015.

${ }^{8}$ ANDRADE, 2015; BADALOTTI, 2015; PALLAORO, 2015. 
mudanças de apropriação simbólica do estádio e mudanças nas formas de torcer. Internamente, os locais da geral (área de ingresso mais barato) se ampliaram e levaram a uma nova espacialidade da torcida, que preferia ficar nas duas arquibancadas atrás dos gols (alas norte e sul, construídas depois, mais modernas e com melhor visão porque eram mais altas) passou a ocupar a ala leste (lateral do campo, conectada com a ala norte). A torcida adversária, que ficava na ala leste, foi deslocada para a área sul. A ala norte passou a ser o local de preferência de torcidas organizadas.

No exterior do estádio, cresceu significativamente o número de vendedores de produtos relacionados ao clube nos dias de jogos (bandeiras, bonés, camisetas, etc.), bem como aumentou a variedade de produtos vendidos. O mesmo ocorreu em relação aos clubes visitantes. Chapecó foi incluída no circuito de vendedores ambulantes de produtos de grandes clubes de Série A. Vários bares foram ampliados e receberam reformas (muitos mudaram a fachada, inserindo símbolos da Chapecoense para aumentar a identificação com o torcedor) para receber o aumento na demanda. As praças e ruas do entorno do estádio se tornaram mais movimentadas em dias de jogos (e de venda de ingresso para grandes jogos), se tornando mais comum torcedores fazerem o esquenta para os jogos tomando cerveja, comendo churrasco ou simplesmente tomando chimarrão (tradição local) e conversando. A Avenida Getúlio Vargas (chamada de Chapecó de "Avenida"), se tornou palco das celebrações das vitórias, acessos e títulos do clube, com grande presença de torcedores fazendo carreatas ou comemorando em bares, lanchonetes ou na própria rua. A não existência de rivais e o ambiente pacífico favoreceu a forte presença de mulheres e crianças tanto no estádio quanto nestas manifestações nas ruas.

Nacionalmente, a Chapecoense se tornou um clube respeitado e, inclusive, com modelo de gestão estudado por especialistas e por outros clubes. (Informação verbal ${ }^{9}$ ). No ranking 2013 de clubes da Confederação Brasileira de Futebol $(\mathrm{CBF})^{10}$, a Chapecoense ocupava a $47^{\mathrm{a}}$ colocação, com 2.754 pontos (CBF, 2013). Neste mesmo ranking, em 2018, o clube do Oeste Catarinense aparece na $14^{\mathrm{a}}$ posição, com 9.010 pontos, havendo ultrapassado clubes tradicionais e de cidades maiores, como Sport, Ponte Preta, Coritiba, Figueirense, Bahia, Vitória, Ceará, Náutico, ABC, Atlético-GO, América-RN, Paysandu, América-MG, Parazráta Santa Cruz, Fortaleza e Guarani (CBF, 2018b).

${ }^{9}$ FELISBINO, 2015; LANG, 2015; PALLAORO, 2015; SANTOS, 2015; VIVIAN, 2015.

${ }^{10} \mathrm{O}$ ranking da $\mathrm{CBF}$ considera os resultados em competições nacionais e internacionais dos últimos cinco anos, conferindo peso maior para os resultados mais recentes. O ranking de um ano refere-se aos resultados dos cinco anos anteriores. Por exemplo, o ranking 2018 considera o quinquênio 2013-2016. 
No $9^{\circ}$ relatório anual Valor das Marcas dos Clubes Brasileiros (BDO, 2016) a Chapecoense aparece como a $21^{\mathrm{a}}$ maior receita do futebol brasileiro ( $\mathrm{R} \$ 46,471$ milhões) e como o $26^{\circ}$ clube com a marca mais valiosa do país, com $\mathrm{R} \$ 33$ milhões ( $\mathrm{R} \$ 10$ milhões a mais que o Náutico, $27^{\circ}$ colocado). Apesar de a Chapecoense não ser citada nos relatórios anteriores, o clube foi o terceiro que mais teve sua marca valorizada em 2016, com 39\% (atrás apenas de Palmeiras, com 56\%, e Ponte Preta, com 41\%). Se considerado o período entre 2012 e 2016, a Chapecoense é o clube com a maior valorização de sua marca: 257\% (contra 187\% do Atlético Mineiro, segundo colocado).

Se partirmos do pressuposto que os clubes são instituições inseridas em um espaço estruturado de disputa - não apenas esportiva, mas também econômica, política e social - e que, portanto, competem entre si (dentro e fora de campo), podemos emprestar os conceitos de campo e capital de Bourdieu (1983). Estes ajudam a expressar a maneira como estas instituições - assim como os indivíduos no campo de Bourdieu - lutam por acúmulo de capital. Este capital (e sua disputa) é primeiramente esportivo - uma partida, um campeonato, títulos - e se dá em um "sistema de relações objetivas entre posições adquiridas (em lutas anteriores" (BOURDIEU, 1983, p. 1). Entretanto, a conquista do capital esportivo pode significar a possibilidade de conquista de mais capital esportivo (por exemplo, um título brasileiro leva a uma vaga na Libertadores da América) e implica na conquista de outros tipos de capital, como o político (aumento da influência, exposição, etc.) e, sobretudo, econômico (premiações de competições, cotas de televisão, patrocínio, etc.). Entretanto, a conversão de capital esportivo em econômico e político não automática e não se dá de forma homogênea. A valorização da marca da Chapecoense demonstra a conversão do capital esportivo em capital econômico (BOURDIEU, 1983), mas também mostra que tal conversão depende de outros fatores (como torcida, mídia, patrocinadores, etc.). Além do retorno futebolístico e financeiro, esta expansão possui implicações simbólicas e geopolíticas para o clube, cidade e região.

A Chapecoense vem aumentando sua inserção no reino da política institucional ${ }^{11}$ do espaço de representação do futebol brasileiro, intensificando e expandindo sua influência e

\footnotetext{
${ }^{11}$ Pode parecer contraditório que a dimensão do vivido abarque um reino de política institucional (nome recebido pelo reino organização no espaço de representação do futebol profissional), no entanto este se apresenta como condição sine qua non para a existência e a perpetuação das experiências de presença, plenamente vividas do futebol profissional. Isto ocorre porque a lógica de aglutinação e identificação do futebol profissional passa necessariamente por clubes (e eventualmente por seleções) (sobre clubismo ver DAMO, 2012). Além disso, o círculo dos reinos (organização, ethos futebolístico e emoções), nos espaços de representação do futebol, se manifestam enquanto representações sociais (MOSCOVICI, 2003), sendo fundamentais para a existência para as categorias de mediação (símbolo, mito, estruturações identitária futebolística e discursos) (GALLEGO CAMPOS, 2006). Portanto, as categorias de mediação somente existem se houver os reinos. No caso do futebol profissional,
} 
criando novas territorialidades. Isto pode ser constatado com a ampliação da participação do clube em competições regionais (a Chapecoense é um dos membros fundadores da Primeira Liga, que congrega alguns dos principais clubes dos estados do Sul, de Minas Gerais, além de Flamengo e Fluminense) e nacionais (a participação na Série A rendeu convites e vagas em competições de categoria de base, como a Copa do Brasil sub-20 e a Copa São Paulo, bem como a melhoria no ranqueamento, o que favorece no sorteio dos conflitos da Copa do Brasil). Além disso, jogar a Série A permitiu que a Chapecoense participasse de seu primeiro torneio internacional, a Copa Sulamericana. Em 2015, o clube foi eliminado nas quartas-de-final pelo River Plate, então campeão da Libertadores, havendo vencido o clube argentino em Chapecó. A mídia argentina deu grande destaque para a participação da "desconhecida" Chapecoense, mas também para o histórico recente de crescimento do "El Hurancán de Oeste” (OLÉ, 2015) (Figura 1).

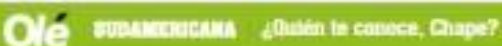

\section{¿Quién te conoce, Ghape?}

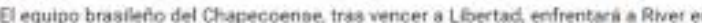
los euartos de la Sudamericana. Coeocet la historia del Huracan del Oeste, aue

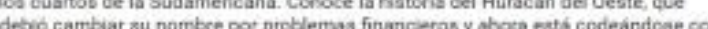
les qrandes en el alano internacional.


Figura 1 - Repercussão da participação da Chapecoense na Copa Sulamericana 2015 Fonte: Olé, 2015

a não consideração das instituições clubísticas na dimensão do vivido esvazia a complexidade da apropriação dos elementos simbólicos, uma vez que para um torcedor, assistir um jogo da Chapecoense é diferente de assistir um jogo de futebol qualquer, produzindo, portanto, representações sociais diferentes. 
Em 2016, a Chapecoense eliminou os argentinos Independiente e San Lorenzo da Copa Sulamericana. A repercussão na Argentina também foi grande, mas desta vez, depois de eliminar o Independiente, o Diário Olé qualificou a Chapecoense como “débil” (OLÉ, 2016), o que demonstra uma mudança no discurso, que está ligado à diferença de tradição entre o clube catarinense e o argentino, o maior ganhador de Libertadores da América. Neste ano, a Chapecoense foi declarada campeã da Copa Sulamericana após a tragédia envolvendo a delegação que estava viajando para Medellín para disputar a final da competição com o Atlético Nacional. O título credenciou a Chapecoense a disputar sua primeira Copa Libertadores da América em 2017. Antes disto, nas vésperas da final da Copa Sulamericana, a Conferederación Sudamericana de Fútbol (Conmebol) já havia qualificado Chapecó como "a nova cidade símbolo do futebol brasileiro" (CONMEBOL, 2016) (Figura 2).

\section{Chapecó, la nueva ciudad simbolo del fútbol brasileño}



Figura 2 - Repercussão do crescimento da Chapecoense pela Conmebol Fonte: Conmebol, 2016.

MUDANÇAS NA PRÁTICA ESPACIAL E NAS REPRESENTAÇÕES DO ESPAÇO 
Em Chapecó, devido ao sucesso da Chapecoense nos últimos anos, símbolos típicos do espaço de representação de futebol passaram a integrar a vida cotidiana irrefletida da instância da prática espacial. Usar a camisa, as cores ou outros símbolos da Chapecoense não tem significado circunscrito aos momentos de presença do espaço de representação, mas passaram a ser um hábito ou expressão identitária de ser de ou viver em Chapecó. Assim, confundem-se ser chapecoense e ser Chapecoense; prática espacial e espaço de representação do futebol.

Esta presença da Chapecoense na vida cotidiana das pessoas favorece a intervenção das representações do espaço. Uma destas forma é através do comércio e atividades econômicas tanto de produtos ligados ao clube quanto de produtos e serviços desvinculados à Chapecoense, mas cujos comerciantes aproveitam o momento para aumentar o faturamento.

Procuramos averiguar os impactos na economia com o acesso da Chapecoense à Série A (período de 2014 a 2016) através da aplicação de questionários em 157 estabelecimentos de comércio e em bares. A maioria registrou incremento nas vendas com a participação da Chapecoense na Série A, chegando a 50\% em algumas lojas. O aumento maior foi nas lojas de materiais esportivos, por comercializar produtos relacionados diretamente ao clube, o que favorece a capitalização do sucesso da Chapecoense (Figura 3).

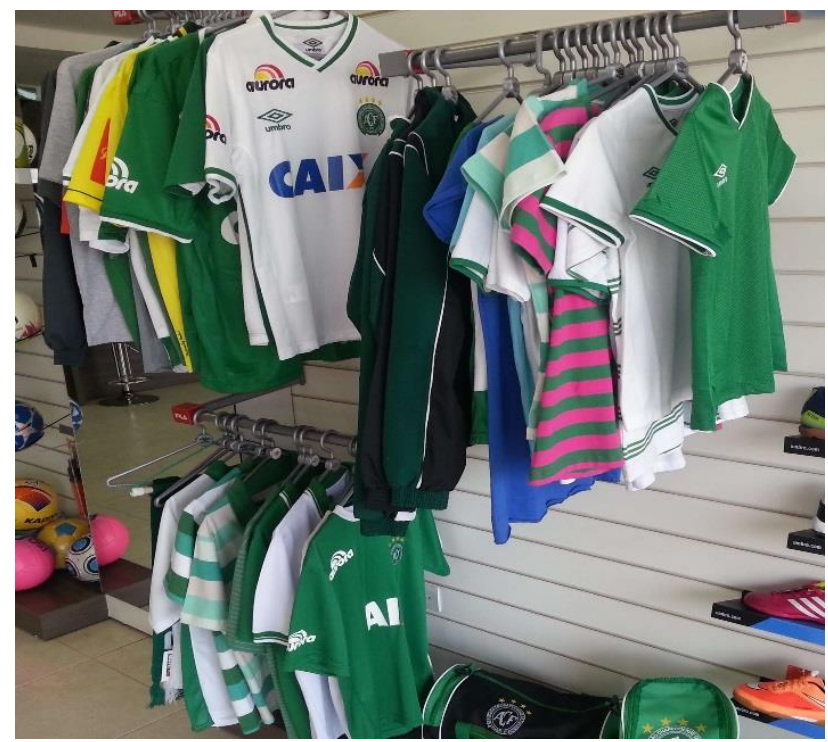




\section{Figura 3 - Comércio de produtos esportivos da Chapecoense}

Fonte: do autor

Restaurantes, hotéis, shopping e lojas em geral registraram maior movimentação, sobretudo em dias de jogo (Informação verbal ${ }^{12}$; G1, 2016). Houve registro de aumento de vendas, inclusive, em lojas que não comercializam produtos ligados ao clube ou ao futebol, como lojas de roupas, de departamento ou material de construção. $\mathrm{O}$ incremento pode não ter relação direta com o sucesso da Chapecoense e está ligado a fatores econômicos mais amplos (como crescimento da cidade - ligado à instância das representações do espaço), mas 94 $(59,9 \%)$ comerciantes entrevistados apontaram que o acesso da Chapecoense à Série A gerou impacto positivo no comércio; 60 (38,2\%) entrevistados afirmaram não ter havido nenhum efeito direto do sucesso da Chapecoense no comércio; enquanto apenas $3(1,9 \%)$ declaram ter piorado (Figura 4). Quando questionados sobre os impactos para a cidade, $135(86,0 \%)$ comerciantes declararam que houve impactos positivos, $21(13,4 \%)$ não responderam ou não souberam responder, enquanto somente um $(0,6 \%)$ disse que houve impacto negativo (Figura $5)$.

Você considera que o acesso da Chapecoense à Série A:

\begin{tabular}{lrr}
\hline & Quantidade & Porcentagem \\
\hline Melhorou o comércio & 94 & $59,9 \%$ \\
Piorou o comércio & 60 & $38,2 \%$ \\
Não houve efeito direto & 3 & $1,9 \%$ \\
Não respondeu/não soube responder & 0 & $0 \%$ \\
Total & $\mathbf{1 5 7}$ & $\mathbf{1 0 0} \%$ \\
\hline
\end{tabular}

\footnotetext{
${ }^{12}$ AGNOLETTO, 2015; ANDRADE, 2015; BADALOTI, 2015; LANG, 2015; NÊS FILHO, 2015; PALLAORO, 2015; STUMPF, 2015; VALMORBIDA, 2015; VIVIAN, 2015.
} 
Figura 4 - Opinião dos comerciantes sobre efeitos no comércio com a participação da Chapecoense na Série A

Fonte: do autor

Você considera que o acesso da Chapecoense à Série A:

\begin{tabular}{lrr}
\hline & Quantidade & Porcentagem \\
\hline Melhorou a cidade & 135 & $86,0 \%$ \\
Piorou a cidade & 1 & $0,6 \%$ \\
Não houve efeito direto & 0 & $0 \%$ \\
Não respondeu/não soube responder & 21 & $13,4 \%$ \\
Total & $\mathbf{1 5 7}$ & $\mathbf{1 0 0 \%}$ \\
\hline
\end{tabular}

Figura 5 - Opinião dos comerciantes sobre efeitos na cidade com a participação da Chapecoense na Série A

Fonte: do autor

Além disso, as empresas têm realizado campanhas para associar o seu nome à Chapecoense seja através de convênios com o clube seja através de propagandas. Atualmente a Aurora é a única empresa local com patrocínio na camisa do clube (Havan e Unimed atuam em Chapecó, mas não tem origem e sede na cidade). Entretanto, antes do acesso à Série A, várias empresas locais já estamparam o nome na camisa da Chapecoense como patrocinadoras: Nostra Casa, Tozzo, Schumann, Planaterra, Inviolável, Desbravador Software, Bauer Express, Britter, Unoesc, Unochapecó entre outras. Entretanto, o valor do patrocínio na camisa aumentou substancialmente devido à maior exposição e à necessidade de aumentar o orçamento do clube (Informação verbal ${ }^{13}$ ). Várias destas empresas continuam patrocinando o clube através de placas e outras ações. Em 2015, 39 empresas pagavam espaço de patrocínio em 48 placas na Arena Condá para o ano todo (Informação verbal ${ }^{14}$ ). Todavia, as placas só eram expostas nos

\footnotetext{
${ }^{13}$ DÁVI, 2015; VIVIAN, 2015.

${ }^{14}$ SANTOS, 2015.
} 
jogos do Campeonato Catarinense, pois nos campeonatos nacionais e internacionais as placas são dedicadas a patrocinadores das competições. De maio a dezembro as placas eram transferidas para o CT da Água Amarela, aparecendo apenas em fotos de jornais ou takes dos treinos da Chapecoense. Segundo alguns entrevistados, a compra das placas é uma forma de manter o vínculo com o clube e de ajudar financeiramente (Informação verbal ${ }^{15}$ ). $\mathrm{O}$ discurso formulado demonstra que decisões econômicas dos atores socioespaciais podem ser influenciada pela dimensão identitária-afetual, o que não exclui possibilidade de lucros econômico e/ou político diretos ou indiretos.

O clube mantém convênio com 188 empresas através do plano de vantagens para sócios (36 de fora da cidade, com destaque para os municípios adjacentes: Pinhalzinho com 24 estabelecimentos e Cordilheira Alta com 8). Em 2015, este número era de 107 empresas, sendo apenas três de fora de Chapecó (ASSOCIAÇÃO, 2016). O clube de vantagens tem sido um mercado importante para as empresas, pois a Chapecoense contava, em novembro de 2016, com cerca de 9 mil sócios que contribuem mensalmente. Antes deste mês, o pico tinha sido 12 mil sócios, número registrado no fim de 2013, o que demonstra a euforia criada com a campanha na Série B e com a perspectiva de disputar a Série A, demonstrando a mobilização da cidade e de seus habitantes em torno do clube.

Além do clube de vantagens para sócios e do comércio dos produtos licenciados - em geral, ligados diretamente ao futebol, roupas, copos/canecas ou de decoração - a marca da Chapecoense se expandiu para outros produtos como cerveja (Figura 6), leite, erva mate e até produtos menos convencionais, como fogões (Figura 7). O sucesso futebolístico contribui para a geração de demandas de produtos e serviços que capitalizam o fato futebolístico e ajudam tanto o clube quanto empresas que associam o nome ao dele se inserirem na vida cotidiana dos habitantes de Chapecó e região, mesmo que de forma irrefletida (LEFEBVRE 1991; SOJA, 1996).

\footnotetext{
${ }^{15}$ DÁVI, 2015; VIVIAN, 2015.
} 


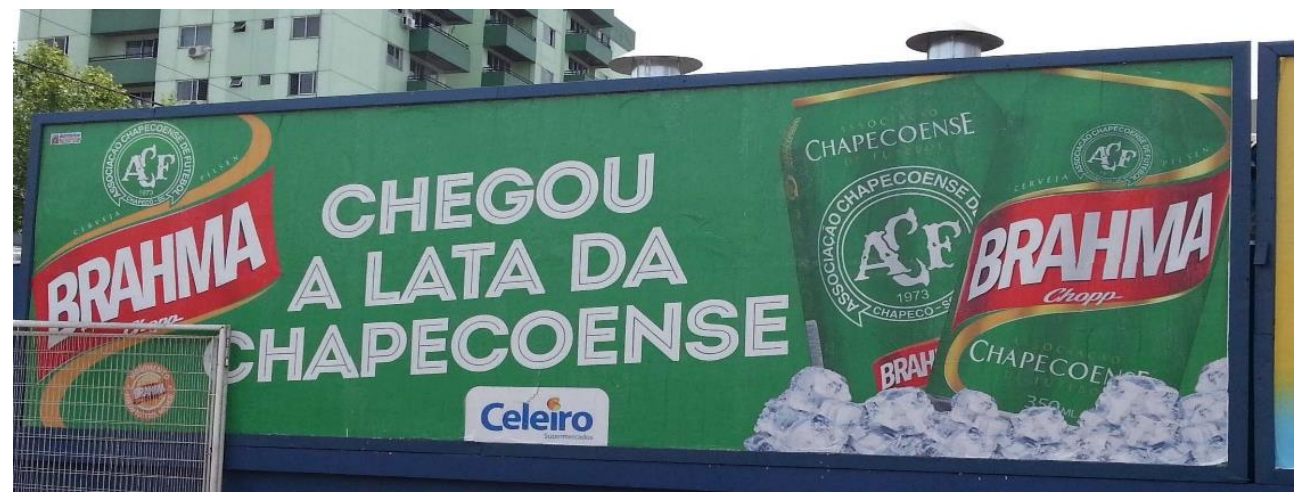

Figura 6 - Campanha de lançamento da latinha de cerveja da Chapecoense

Fonte: do autor

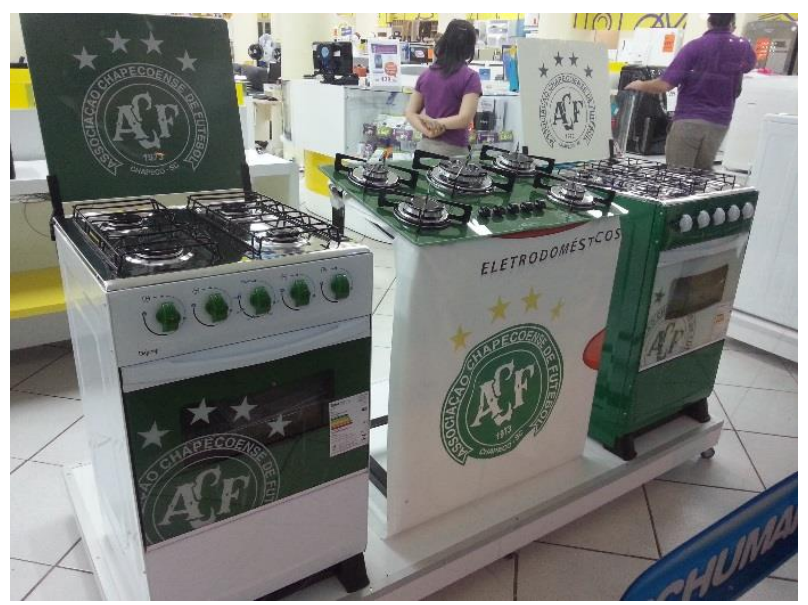

\section{Figura 7 - Fogões da Chapecoense}

Fonte: do autor

O fato da Chapecoense ser o único clube da cidade e o único time da região polarizada por Chapecó (oeste de Santa Catarina, noroeste do Rio Grande do Sul e sudoeste do Paraná) a disputar competições nacionais, faz com que o clube tenha muito pouca rejeição. Isto estimula as empresas associarem o nome à Chapecoense e os estabelecimentos colocarem símbolos do clube em suas placas de identificação, vitrines ou fachadas (Figura 8). Ações como estas seriam 
impensadas - a não ser em comércio muito segmentado - em cidades com dois ou mais clubes, em que a rivalidade entre eles poderia prejudicar as vendas da loja que se associou a um dos clubes, bem como poderia gerar depredações.



Figura 8 - Símbolo da Chapecoense na fachada de uma boate

Fonte: do autor

Esta mesma lógica pode ser observada nas intervenções públicas no espaço urbano. Há claramente uma apropriação do capital esportivo (BOURDIEU, 1983) da Chapecoense por parte do poder público, que o transfere para a instância da prática espacial, o convertendo em capital político transfigurado de estruturação identitária. Isto pode ser observado em intervenções mais despretensiosas, como na pintura em verde e branco de meios-fios das ruas da cidade, sobretudo no Centro (Figura 9), mas também pode ser visto na tentativa de associação da marca e, consequentemente, o sucesso da Chapecoense com a marca e, consequentemente, a administração da prefeitura. Na Figura 10, esta associação fica clara com o uso de "a gente" para se referir ao acesso da Chapecoense à Série A. Logo abaixo da frase estão os símbolos da Chapecoense e da Prefeitura Municipal de Chapecó, reforçando a ideia de "a gente". 




Figura 9 - Pintura de meios-fios e postes com as cores da Chapecoense, no Centro de Chapecó

Fonte: do autor

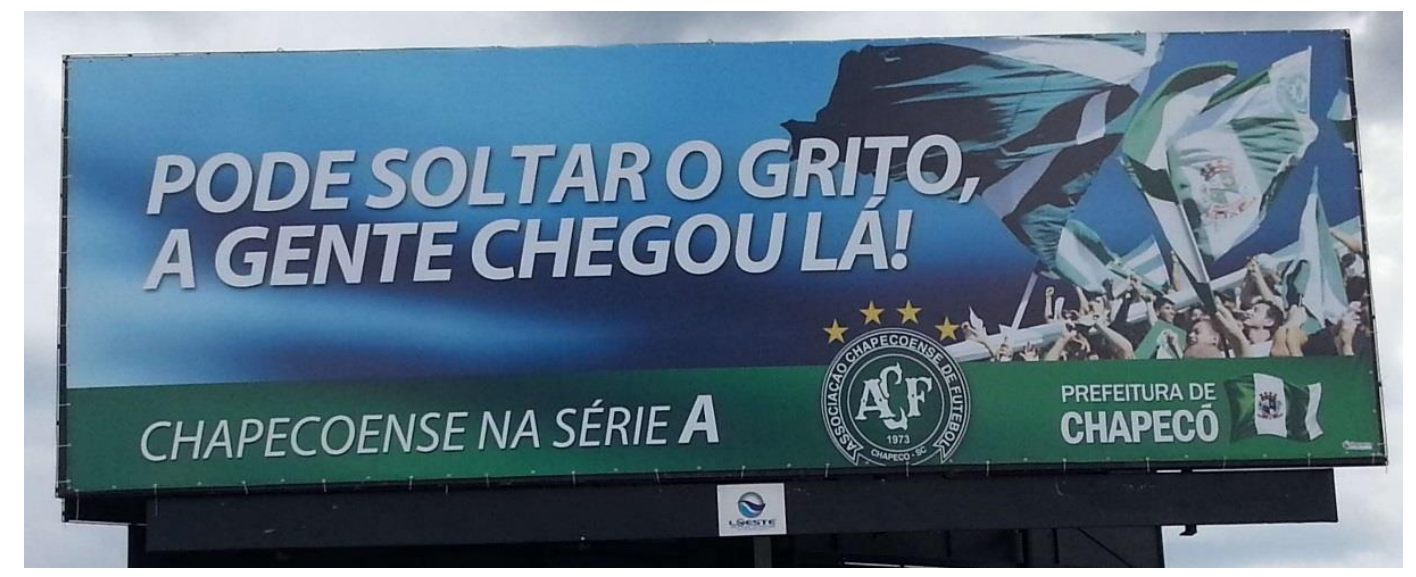

Figura 10 - Propaganda da Prefeitura utilizando a imagem da Chapecoense Fonte: do autor 
Entretanto, este uso político da marca da Chapecoense ocorre em um contexto de histórica parceria entre clube e prefeitura, na qual o poder municipal tem sido de suma importância no aporte financeiro e logístico para a Chapecoense. A Arena Condá, estádio em que o clube manda seus jogos, é da Prefeitura - que tem contribuído também na manutenção e ampliação do mesmo. Além disso, até 2015, a sede administrativa do clube ficava em prédios cedidos pela municipalidade. No final de 2015, foi inaugurada a nova sede administrativa da Chapecoense, cerca de 100 metros de distância da antiga. O clube aluga a atual estrutura, mas mantém alguns setores, como as categorias de base em instalações da Prefeitura.

Tal proximidade institucional ajuda reforçar discursos, que se materializam no espaço (como placas ou construções) ou que aparecem de forma mais fluída. Uma destas ocorreu na campanha para a Prefeitura Municipal de Chapecó, em 2016, em que um dos temas centrais de discussão foi a relação entre o poder público municipal e a Chapecoense, bem como do uso político do clube. O candidato a reeleição acusou o partido de oposição de abandonar a Chapecoense em décadas passadas, reforçando o efeito de sentido (contido na placa, da Figura 10, por exemplo) de que o sucesso da Chapecoense está ligado ao sucesso da gestão pública de seu grupo político. A candidata da oposição, por sua vez, acusou o candidato a reeleição de fazer uso político de um patrimônio cultural da cidade, tentando partidarizar a paixão dos moradores de Chapecó. É possível que esta discussão não tenha influenciado diretamente o resultado das eleições, mas ajuda a demonstrar como três instâncias da espacialidade se relacionam intimamente e até se confundem.

Tais relações ficam claras nas declarações dos entrevistados. Para eles, o principal impacto para a cidade da ascensão da Chapecoense nos últimos anos é o reconhecimento de Chapecó em todo o Brasil. Eles apontam que a marca Associação Chapecoense de Futebol tem muita credibilidade, devido à rápida ascensão (da Série D a Série A) e à administração realizada no clube nos últimos anos (Informação verbal ${ }^{16}$ ). Esta marca é automaticamente associada à cidade. Com pouco mais de 200 mil habitantes (IBGE, 2016), Chapecó é o menor dos 11 municípios que participaram da Série A de 2016, sendo a Chapecoense o clube de cidade c\$\&8 menos de 300 mil habitantes com mais participações na Série A desde $2006^{17}$. Desta forma, a

\footnotetext{
${ }^{16}$ FELISBINO, 2015; LANG, 2015; PALLAORO, 2015; SANTOS, 2015; STUMPF, 2015; VIVIAN, 2015.

${ }^{17}$ A Chapecoense tem quatro participações na Série A (2014-2017). Os outros municípios com menos de 300 mil habitantes com participação na Série A desde 2006 são: Ipatinga-MG, Criciúma-SC, Barueri-SP e Santo AndréSP (os dois últimos, integrantes da Região Metropolitana de São Paulo).
} 
exposição do clube nos meios de comunicação canaliza atenção para a cidade, o que segundo empresários tem contribuído para os negócios (Informação verbal ${ }^{18}$ ).

Os entrevistados não apontaram nenhuma mudança negativa significativa na vida cotidiana de Chapecó. Ao serem questionados sobre os impactos na cidade, todos apontaram mudanças positivas, mas alguns foram categóricos ao dizer que não houve nenhum impacto negativo (Informação verbal ${ }^{19}$ ). Rafael Henzel (Informação verbal ${ }^{20}$ ) foi o único a enumerar mudanças que poderiam ser encaradas como negativas, apesar de achar que tais questões eram inerentes a participação da Chapecoense na Série A, como o aumento no preço do ingresso e a necessidade de interditar ruas em dias de jogos - o que ocorre de forma parcial e com poucas horas de antecedência às partidas com menor apelo, mas de forma mais intensa, ou seja, fechamento total e de maior número de ruas, com maior antecedência em dia de jogos com maior apelo e com televisionamento em TV aberta.

\section{CONSIDERAÇÕES FINAIS}

As modificações no espaço social de Chapecó - se aproximando de uma configuração de espaço diferencial (LEFEBVRE, 1991) - devido ao recente sucesso esportivo da Chapecoense - que tem como principal marco o acesso à Série A do Campeonato Brasileiro em 2013 - são potencializadas pelo tamanho de Chapecó e pelo fato da Chapecoense ser o único time da cidade. Estes dois fatores permeiam praticamente todas as mudanças nas três instâncias da espacialidade, que já expusemos e analisamos.

No que se refere ao tamanho da cidade, é possível constatar que é raro um time de cidade de média disputar a elite do futebol brasileiro, sobretudo de uma cidade do interior. No atual formato do Brasileirão (com 20 times, desde 2006), apenas cinco cidades com menos de 300 mil habitantes (IBGE, 2016) tiveram representantes na Série A, sendo a Chapecoense o clube destas cidades com mais participações (ao menos 4, entre 2014 e 2017). Desta forma, a participação da Chapecoense é vista como uma oportunidade de crescimento do clube (futebolística, política, simbólica e financeiramente) e da cidade que, apesar de importante p\$\$9 agroindustrial e metalmecânico, experimenta uma exposição nacional e internacional inédita, alavancada pelo sucesso da Chapecoense. Tal aspecto fica evidente: (1) para o clube - com o

${ }^{18}$ BENINI, 2015; BORDIGNON, 2015; DÁVI, 2015; NÊS FILHO, 2015; PALLAORO, 2015; PERONE, 2015; SANTOS, 2015; STUMPF, 2015; VIVIAN, 2015; ZANONI, 2015. 
acesso a competições nacionais e internacionais, com o aumento no peso político estadual e nacionalmente, com o incremento orçamentário, etc. - e (2) para a cidade - com a maior exposição de seu nome e associação com uma administração futebolística bem-sucedida, expandindo oportunidades de negócios e aumentando a inserção de Chapecó em campos da política estadual, regional, nacional e internacional.

O fato de a Chapecoense ser o único clube da cidade e representar nacionalmente toda uma região (que se estende do oeste de Santa Catarina ao sudoeste do Paraná e noroeste do Rio Grande do Sul) contribui decisivamente no estabelecimento de estruturações identitárias (ligadas à inexistência de rivalidade local, à baixíssima rejeição em Chapecó e na região e à associação direta do clube com a cidade e região). Isto permite uma organização do espaço (urbano) local, através do poder público e da iniciativa privada, permeada por elementos simbólicos da Chapecoense (cores, distintivo, etc.) apropriados em uma lógica econômica, política e institucional, construindo complexas e peculiares relações que vão do uso da marca Chapecoense para impulsionar a venda de produtos até a utilização política do clube em períodos eleitorais. Em cidades com mais de um clube, em que a rivalidade faz parte do cotidiano, como é o caso de Porto Alegre, Curitiba e Florianópolis estes usos simbólicos ganham outras formas e são mais restritos, já que manifestar torcida ou apoio a apenas um dos clubes gera descontentamento (que pode se converter em violência) por parte da torcida do seu rival.

É possível perceber a centralidade que o futebol pode assumir na estruturação espacial de uma cidade e/ou região. Portanto, trata-se de um elemento que não pode ser ignorado ou relegado a segundo plano. Isto ficou ainda mais claro depois do desastre aéreo envolvendo a delegação da Chapecoense, em novembro de 2016. Além da comoção ter transcendido as fronteiras estaduais e nacionais no mundo do futebol, as respostas de solidariedade se estenderam para os mais diversos setores de atividades, sendo responsáveis, inclusive, em estreitar relações entre Brasil e Colômbia. Mesmo que o desastre aéreo e seus desdobramentos terem ficado propositalmente fora do recorte deste trabalho, este exemplo ajuda a demonstrar a força do futebol como elemento simbólico e identitário de uma sociedade, que se materializa espacialmente. 
Desta forma, faz-se necessário avançar em estudos semelhantes em outras cidades, sobretudo em cidades médias - carentes de produção científica sobre os diferentes aspectos de sua espacialidade, em especial ligados a questões simbólicas, como o futebol. É fundamental que a Geografia ocupe esta lacuna através de estudos de caso, mas também através do avanço de abordagens teóricas seja na visão lefebvriana seja em outras perspectivas, que podem se converter em grandes contribuições para áreas da Geografia Cultural e Social e da Geografia Urbana.

\section{AGRADECIMENTOS}

Agradecemos a todos que tornaram esta pesquisa possível, sobretudo aos entrevistados. Alguns dos entrevistados estavam dentre as vítimas do desastre aéreo de 29/11/2016. Outros estão ajudando a reconstruir o clube. Este artigo é uma homenagem aos eternos campeões.

\section{REFERÊNCIAS}

ASSOCIAÇÃO Chapecoense de Futebol. Clube de Vantagens. Disponível em: <http://www.chapecoense.com/2016/clubedevantagens>. Acesso em 30 out. 2016.

- Demonstrações financeiras em 31 de dezembro de 2016 e de 2015 e relatórios de auditores independentes. Disponível em: <http://www.fcf.com.br/wpcontent/uploads/2017/04/04/balanco-ass-chap-2016-publicado-em-28-04-2017.pdf>. Acesso em 15 mar. 2017.

GALLEGO CAMPOS, F. R. O espaço de representação do futebol: uma apreensão do futebol como um elemento sociocultural e espacial. Ra'e Ga. Curitiba, v. 11, p. 35-49, 2006.

GALLEGO CAMPOS, F. R.; BETTONI, M. Análise da ocorrência de faltas escolares devido ao futebol em duas instituições do ensino de Chapecó, Santa Catarina. Cadernos de Estudos Sociais. Rio de Janeiro, v. 32, s. 2, p. 88-102, 2016.

BDO. $9^{\circ}$ Valor das marcas dos clubes brasileiros: finanças dos clubes. BDO Publicações, 2016.

BELLANI, E. M. O futebol e a ocupação do espaço social em Chapecó (1919-1973). Chapecó: Arcus, 2007.

BOURDIEU, P. Questões de sociologia. Rio de Janeiro: Marco Zero, 1983.

CONFEDERAÇÃO BRASILEIRA DE FUTEBOL. CBF. Ranking nacional das federações 2018. Disponível em: 〈http://cdn.cbf.com.br/content/201712/20171204171859.pdf〉. Acesso em 15 mar. 2017.

Ranking nacional de clubes - temporada 2013. Disponíel em: <http://cdn.cbf.com.br/content/201212/28291933.pdf $\rangle$. Acesso em 15 abr. 2018. 
Ranking nacional dos clubes 2018. Disponível em: 〈https://cdn.cbf.com.br/content/201712/20171204170858_0.pdf $\rangle.$ Acesso em 15 abr. 2018. CONFEDERACIÓN Sudamericana de Fútbol. CONMEBOL. Chapecó, la nueva ciudad símbolo del fútbol brasileño. Disponível em: <http://www.conmebol.com/es/chapeco-lanueva-ciudad-simbolo-del-futbol-brasileno>. Acesso em 15 mar. 2017.

DAMO, A. S. Paixão partilhada e participativa: o caso do futebol. História Questões e Debates. Curitiba, v. 57: 45-72, 2012.

FRANCO JÚNIOR, H. Brasil, país do futebol?. Revista USP. São Paulo, v. 99: 45-56, 2013. G1. Vitória da Chapecoense sobre o San Lorenzo pode levar time à final da SulAmericana. Disponível em: $\quad$ http://g1.globo.com/sc/santa-catarina/rbsnoticias/videos/t/edicoes/v/vitoria-da-chapecoense-sobre-o-san-lorenzo-pode-levar-time-afinal-da-sul-americana/5464530/>. Acesso em 23 mar. 2017.

GIL FILHO, S. F. Espaço de representação: epistemologia e método. ANPEGE, Florianópolis, 2003.

HALL, S. Identidade cultural na pós-modernidade. Rio de Janeiro: DP\&A, 2005.

INSTITUTO Brasileiro de Geografia e Estatística. IBGE. Estimativas populacionais para os municípios e para as Unidades da Federação brasileiros em 01.07.2016. Disponível em: <http://www.ibge.gov.br/home/estatistica/populacao/estimativa2016/estimativa_dou.shtm>.

Acesso em 15 mar. 2017.

LEFEBVRE, H. The production of space. Oxford: Blackwell, 1991.

La presencia y la ausencia: contribución a la teoría de las representaciones.

México: FCE, 2006.

Critique of everyday life - volume 2: foundations for a sociology of the everyday. London: Verso, 2008.

MAFFESOLI, M. O tempo das tribos: o declínio do individualismo nas sociedades de massa. Rio de Janeiro: Forense Universitária, 2006.

MASCARENHAS, G. Football, globalisation and local identity in Brazil. Esporte e Sociedade. Rio de Janeiro, v. 3: 1-14, 1999.

. Um jogo decisivo, mas que não termina: a disputa pelo sentido da cidade nos estádios de futebol. Cidades. Presidente Prudente, v. 10, n. 17: 142-170, 2013.

MOSCOVICI, S. Representações sociais: investigações em psicologia social. Petrópolis: Vozes, 2003.

OLÉ. ¿Quién te conoce, Chape?. Disponível em: <http://www.ole.com.ar/futbolinternacional/sudamericana/Copa_Sudamericana_0_1441656018.html>. Acesso em 23 mar. 2017.

"Mi equipo tiene identidad". Disponível em:

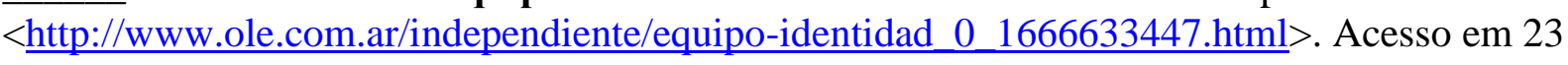
mar. 2017.

SHIELDS, R. Lefebvre, love and struggle: spatial dialectics. London: Routledge, 1999.

SOJA, E. W. Thirdspace. Oxford: Blackwell, 1996. 


\section{ENTREVISTAS}

AGNOLETTO, Cleiton César (jornalista, radialista, narrador). Entrevista ao autor. 10 abr. 2015.

ANDRADE, Jorge Luiz de (roupeiro da Chapecoense). Entrevista ao autor. 14 mar. 2015.

ARAÚJO, Anderson R. Paixão (preparador físico da Chapecoense de 2011 a 2016 e da Seleção Brasileira). Entrevista ao autor. 22 maio 2015.

BADALOTI, Sérgio Alcides (jornalista, radialista, comentarista esportivo). Entrevista ao autor. 08 abr. 2015.

BENINI, José Carlos (empresário, presidente da Câmara de Dirigentes Logistas de Chapecó). Entrevista ao autor. 14 maio 2015.

BORDIGNON, Jandir (vice-presidente da Chapecoense, empresário). Entrevista ao autor. 10 jun. 2015.

CONSTANTE, Nivaldo Martins (goleiro da Chapecoense de 2006 a 2016, jogou as Séries D, C, B e A pelo clube). Entrevista ao autor. 22 maio 2015.

DÁVI, Davi Barela (empresário, conselheiro e patrocinador). Entrevista ao autor. 18 abr. 2015.

FELISBINO, Richarlyson Barbosa (jogou pela Chapecoense em 2015, tem passagem por grandes clubes e Seleção Brasileira). Entrevista ao autor. 14 mar. 2015.

LANG, Diógenes (secretário municipal de desenvolvimento econômico). Entrevista ao autor. 31 mar. 2015.

LIMA, Rafael Ramos de (zagueiro da Chapecoense de 2012 a 2016, jogou as Séries C, B e A pelo clube). Entrevista ao autor. 22 maio 2015.

NÊS FILHO, Plínio David de (presidente do conselho deliberativo da Chapecoense). Entrevista ao autor. 11 jun. 2015.

PALLAORO, Sandro Luiz (presidente da Chapecoense, empresário, patrocinador). Entrevista ao autor. 28 maio 2015.

PERONE, Eduardo José (Dirigente executivo da Associação Comercial Industrial de Chapecó). Entrevista ao autor. 15 maio 2015.

RODRIGUES, Wanderson Pereira (volante da Chapecoense de 2012 a 2015, jogou as Séries C, B e A pelo clube). Entrevista ao autor. 14 mar. 2015.

SANTOS, Leandro Andrei Copetti (diretor de marketing da Chapecoense). Entrevista ao autor. 27 mar. 2015.

SOUZA, Odair (ou Neném, na Chapecoense desde 2009, é o único jogador tricampeão catarinense pelo clube, jogou as Séries D, C, B e A). Entrevista ao autor. 14 mar. 2015.

STUMPF, Mauro Luís (vice-presidente de futebol da Chapecoense, empresário). Entrevista ao autor. 14 mar. 2015.

VALMORBIDA, Rafael Henzel (jornalista, radialista, narrador). Entrevista ao autor. 08 abr. 2015. 
VIVIAN, Gilson (dirigente da Chapecoense, empresário, patrocinador). Entrevista ao autor. 23 mar. 2015.

ZANONI, Bento (empresário, patrocinador, presidente da Associação Comercial Industrial de Chapecó). Entrevista ao autor. 15 maio 2015.

Recebido em 16 de maio de 2017.

Aceito em 24 de maio de 2018. 